The treaty of Lisbon and European Union trade policy: A political-economic analysis

Christophe Crombez and Wim Van Gestel

DEPARTMENT OF MANAGERIAL ECONOMICS, STRATEGY AND INNOVATION (MSI) 


\title{
The Treaty of Lisbon \\ and European Union Trade Policy: \\ A Political-Economic Analysis
}

\author{
Christophe Crombez \\ Wim Van Gestel
}

September 2011

\begin{abstract}
This paper presents a game-theoretical analysis of European Union (EU) trade policy and the Lisbon Treaty's impact on it. Specifically, it develops spatial models of the EU's international trade negotiations process, and analyzes the European Parliament's increased involvement in it as a result of the introduction of the Parliamentary consent requirement for international trade agreements. We find that the Council's right to set a negotiating mandate in trade negotiations is equivalent to an amendment right, and that the Commission's right to propose a negotiating mandate to the Council is comparable to a monopoly proposal right in the negotiation process with the trade partner. We further conclude that the Parliament's enhanced role limits the Commission's ability to set policy and conclude negotiations. Even though it represents a domestic constraint for the Commission, the Parliament's involvement does not reinforce the Commission's bargaining position in international negotiations. The Commission can use the negotiating mandate to improve its bargaining position instead.
\end{abstract}




\section{Introduction}

The European unification process, launched in the 1950s with political objectives in mind, has progressed farther on economic issues than in any other policy area. The internal market and the monetary union, even though they may be in crisis today, precisely because of a lagging political unification, stand out as its most momentous achievements. Other economic policies that are now the exclusive competence of the European Union (EU) include competition policy and external trade.

This paper focuses on the EU's external trade policy, referred to in the EU treaties as the common commercial policy. Since the Treaty of Rome entered into force in 1958, the EU member states have delegated the conduct of trade policy to the EU and specifically to the Commission, a political body appointed by the EU's other two main political institutions, the Council and the European Parliament (EP). ${ }^{1}{ }^{2}$ As a result the Commission conducts international trade negotiations for the member states. The EU, as represented by the Commission, is also a member of the World Trade Organization together with its member states.

The Treaty of Lisbon, which was ratified in November 2009, altered EU trade policy in three important ways. ${ }^{3}$ First, external trade became the exclusive competence of the EU. In particular its authority was extended to include all issues concerning trade in services, trade-related aspects of intellectual property, 
and foreign direct investment. ${ }^{4}$ As a result trade agreements no longer need to be ratified by national parliaments.

Second, the use of qualified majority voting in the Council was extended. ${ }^{5}$ Unanimity still applies, however, to trade in cultural and audiovisual services and social, education and health services, if cultural or linguistic diversity or the national organization of these services is threatened. ${ }^{6}$

Third, the EP is now more involved in trade policy. The Commission needs to report to it during trade negotiations and its consent is required for the adoption of trade agreements. ${ }^{7}$ Moreover, the codecision procedure now applies to trade legislation. ${ }^{8} 9$ Prior to the Lisbon Treaty the consultation procedure applied. Under consultation the EP was merely consulted, but its opinion could be ignored. Under codecision the $\mathrm{EP}^{\prime} \mathrm{s}$ approval is required for the adoption of legislation, and it can amend Commission proposals together with the Council.

The Lisbon Treaty's changes to EU trade policy addressed the three objectives set out in the 2001 Laeken Declaration that launched the process of treaty reform: the enhancement of its effectiveness in world politics, its decisionmaking efficiency, and its democratic character. Bringing trade policy into the exclusive competence of the EU arguably increases its effectiveness, since member states weigh more on international negotiations if they act as one. The use of qualified majority rule rather than unanimity improves its efficiency. The $\mathrm{EP}^{\prime}$ s increased involvement, finally, improves its democratic character. 
The EU's legislative procedures and the EP's increased involvement in the legislative process have received considerable attention in the political economic literature thus far. ${ }^{10}$ Crombez $(1997,2001)$ finds that the EP's involvement under codecision reduces the sets of policies that can be adopted and diminishes the powers of the Commission. Applying his analysis to EU trade policy suggests that efforts to liberalize trade may suffer as a result of the Lisbon Treaty, if the EP is more protectionist than the Commission or the pivotal member states. If the EP is less protectionist than the Commission and the pivotal member state, the prospects for trade liberalization are unaffected.

In this paper we focus on international trade negotiations, rather than the legislative process, and study how they are affected by the increased involvement of the EP. We formulate a game-theoretical model of the EU's trade negotiations process. The model yields predictions regarding the outcomes of trade negotiations and how trade agreements are affected by the EP's involvement. It offers important insights into the role of the negotiating mandate and its impact on trade agreements. The mandate outlines what policies the Commission can agree to during trade negotiations. The Council sets it at the Commission's proposal prior to the start of the negotiations.

We find that the Commission includes in its mandate the policies that satisfy the following two conditions. First, they are preferred to the status quo by a qualified majority of the member states, the EP, and the trade partner. Policies that satisfy this condition can be adopted. Second, no policy that can be adopted 
is preferred to them by all member states. If the mandate includes policies that do not satisfy this second condition, it is amended. If the Commission has all the bargaining powers in its negotiations with the trade partner, it successfully proposes the policy it likes most from among the policies in its mandate. If it does not have all the bargaining powers, it can achieve the same results by restricting its mandate. The EP's increased involvement since the Lisbon Treaty's ratification does not strengthen the Commission's bargaining powers in the negotiation process. It merely adds a constraint and thus reduces the prospects for trade liberalization.

The paper is organized as follows. In the next section we present our model of EU trade negotiations. The third section studies what trade agreements emerge from the negotiation process. In the fourth section we analyze the role of the negotiating mandate, and in the fifth section we examine the impact of the Lisbon Treaty. Section six presents the conclusions.

\section{A Model of EU Trade Negotiations}

\subsection{Actors and Preferences}

The political actors in our model of EU trade negotiations are the $m$ member states, the Members of the European Parliament (MEPs), the Commissioners, and the EU's trade partner. We assume that these actors care 
about policy and have Euclidean preferences. That is, they have ideal policies and prefer policies that are closer to rather than farther away from their ideal policies. Thus, they can be represented by points in the policy space. We assume for simplicity that the policy space $P \subset \Re$ is one-dimensional. ${ }^{11}$ The dimension could represent the degree of trade liberalization, for example.

The European Parliament (EP) and the Commission use simple majority voting, and there are no restrictions on amendments. As a consequence, the analysis of trade negotiations can be simplified by focusing on the ideal policies of the median Commissioner and the median MEP. Suppose the status quo is to the right (left) of the median Commissioner's ideal policy, then the median Commissioner and all Commissioners on his left (right) then want a move to the left (right). As a result, any policy is defeated in the Commission by policies that are closer to the median Commissioner's ideal policy (e.g. Black, 1958). A similar reasoning applies to the EP. The Commission and the EP can thus be treated as unitary actors with ideal policies equal to their medians' ideal policies.

The Council is not represented as a unitary actor because it uses Qualified Majority Voting (QMV) to adopt negotiating mandates and trade agreements and unanimity rule to amend mandates. Nonetheless, the analysis of trade negotiations can be simplified by focusing on the member states that are pivotal under the QMV and unanimity rules. Under the QMV rule, 255 votes out of a total of 345 are currently needed to defeat the status quo. ${ }^{12}$ The member state $a$ that is pivotal for a rightward move thus has an ideal policy to the left of the 
member state with the median vote. In particular, it is the member state with the 91st vote (from the left). Member state $a$ and the member states to its right then have at least 255 votes, and the member states to its right do not constitute a qualified majority without it. Similarly, the member state $b$ that is pivotal for a move to the left is the member state with the 255th vote. It is to the right of member state $a$ and the member state with the median vote. Thus, if it wants to move to the left, member state $a$ does too. Under unanimity rule the two most extreme member states 1 and $m$ are pivotal.

In sum, there are seven potentially relevant actors in trade policy making: (1) the Commission, as represented by the median Commissioner; (2) the EP, as represented by the median MEP; $(3,4,5,6)$ the member states $1, a, b$ and $m$; and (7) the EU's trade partner. We refer to member states $a$ and $b$ as the pivotal member states, and to member states 1 and $m$ as the extreme member states.

\subsection{The Negotiation Process}

The sequence of events in the negotiation process is shown in Figure 1. First, the Commission offers to start trade negotiations with a trade partner. ${ }^{13}$ In particular it proposes a negotiating mandate to the Council. A negotiating mandate is a set $N M \subseteq P$ of trade agreements the Commission is allowed to negotiate with the trade partner. It provides an opportunity for the Council to limit what the Commission can do during the trade negotiations. 
--- Figure 1 about here ---

Next, the Council can amend the mandate by unanimity. We assume for simplicity that only one member state $k$ can propose an amendment. The (amended) mandate subsequently needs to obtain qualified majority support in the Council for approval. If it is rejected, no negotiations take place and the status quo prevails. If the mandate is approved, by contrast, negotiations with the trade partner begin.

The Commission conducts the negotiations for the EU. There is no formal procedure for the negotiations between the Commission and the trade partner. We assume for simplicity that during the negotiations the Commission proposes a trade agreement to the trade partner.

The trade partner can then accept or reject the proposed agreement. If she rejects, no agreement is concluded and the status quo prevails. If the trade partner accepts the proposed agreement, it is subsequently presented to the Council for approval. Approval requires qualified majority support. If the agreement falls short of a qualified majority in the Council, the status quo prevails.

Since the ratification of the Lisbon Treaty the EP also needs to approve the trade agreement for adoption. If it rejects, the status quo prevails. If both the EP and a qualified majority in the Council accept, the trade agreement is adopted. 
The model incorporates complete and perfect information. We use the subgame perfect Nash equilibrium concept.

\section{Trade Agreements}

In this section we characterize the equilibrium trade agreement as a function of the actors' preferences and the location of the status quo. When initiating trade negotiations and proposing a negotiating mandate in the first step of the negotiation process the Commission looks ahead and considers what trade agreements can get adopted. Similarly, the other political actors look ahead in the subsequent stages of the process. For that reason we use backward induction to study what trade agreements are adopted.

In the last two stages of the negotiation process, as shown in Figure 1, the Council and the EP vote on the trade agreement. If either rejects the agreement, the status quo prevails. The member states and the EP thus compare the agreement to the status quo. They vote in favor of the agreement if they prefer it to the status quo. For an agreement to be adopted in the last two stages of the negotiation process it thus has to be preferred to the status quo by the EP and a qualified majority in the Council. An agreement can thus be adopted only if the EP and the pivotal member states want to move in the same direction away from the status quo. 
Let $A_{E P}$ be the EP's acceptance set, that is, the set of policies the EP prefers to the status quo. It is the set of policies that are closer to its ideal policy than is the status quo. That is, the set $A_{E P}=\left[\min \left\{2 p_{E P-}-q, q\right\}, \max \left\{2 p_{E P-}-q, q\right\}\right]$, where $q$ is the status quo and $p_{E P}$ is the EP's ideal policy. The policy $2 p_{E P}-q$ is the policy that makes the EP indifferent to the status quo. It is equidistant from the EP's ideal policy as is the status quo. Similarly, let $A_{Q M}$ be the qualified majority's acceptance set, the set of policies a qualified majority prefers to the status quo. That is, $A_{Q M}=\left[\min \left\{2 p_{b}-q, q\right\}, \max \left\{2 p_{a^{-}} q, q\right\}\right]$, where $p_{a}$ and $p_{b}$ are the ideal policies of the two pivotal member states. The EU's acceptance set $A_{E U}$, the set of agreements that can be adopted in the last two stages of the negotiation process, is then the set $A_{E P \cap} \cap A_{Q M}{ }^{14}$

Figure 2 illustrates what agreement emerges from the negotiations for a particular configuration of ideal policies. In the Figure the trade partner $T$ is on the far right of the policy space. She wants more trade liberalization than the other actors, for example. The EP is to the left of the pivotal member states, $M S_{a}$ and $M S_{b}$, and is thus more protectionist than they are, but not as much as the most protectionist member state $M S_{1}$. The Commission $C$ is on the right, more so than the least protectionist member state $M S_{n}$, but not as far to the right as the trade partner. The status quo is at the very left of the policy space.

--- Figure 2 about here --- 
The Figure shows the EP and qualified majority acceptance sets for the particular configuration of ideal policies. As the EP is more protectionist than are the pivotal member states, the EP is the crucial actor in the last two stages of the process. If the Commission can obtain its approval for the agreement, the agreement is adopted. The EU's acceptance set is thus equal to the $\mathrm{EP}^{\prime} \mathrm{s}$ acceptance set. If member state $a$ were more protectionist than the EP, member state $a^{\prime}$ s acceptance set would be the EU's acceptance set.

In the sixth stage of the process the EU's trade partner considers the Commission's proposed trade agreement. If she accepts the proposed agreement and the EP and the Council subsequently approve it as well, the proposed agreement is adopted. Otherwise the status quo prevails. The partner thus accepts the agreement if she prefers it to the status quo. In particular she votes in favor if the agreement is closer to her ideal policy than is the status quo, that is if it is in her acceptance set $A_{T}=\left[\min \left\{2 p_{T-q}, q\right\}, \max \left\{2 p_{T}-q, q\right\}\right]$. The set $A_{N P}$ of proposed agreements that can be adopted in the last three stages of the negotiation process is then the set $A_{N P}=A_{T} \cap A_{E U}$. A move away from the status quo can thus only be adopted if the pivotal member states, the EP and the trade partner all want to move in the same direction away from the status quo. In what follows we assume that they all want to move to the right.

In Figure 2 the trade partner wants to move farther away from the status quo than does the EP: it wants more trade liberalization. It thus accepts all trade 
agreements that the EP accepts. The acceptance set in the negotiation process is thus equal to the EP's acceptance set.

In the fifth stage of the process the Commission proposes a trade agreement. It can propose any agreement within the negotiating mandate $N M$ that was approved in the previous stage. For the agreement to be adopted it needs to be preferred to the status quo by the trade partner, the EP and a qualified majority in the Council: it needs to be in the acceptance set $A_{N P}$. Otherwise the status quo prevails. The Commission thus successfully proposes the agreement $p^{*}$ it prefers most from among the policies that are in the set $N M \cap A_{N P}$.

In equilibrium this set is non-empty. In fact, the Commission has no incentive to propose a mandate that includes policies that are not in the acceptance set $A_{N P}$. Such policies cannot be adopted. Including them in the mandate is thus equivalent to including the status quo. The status quo is in the acceptance set $A_{N P}$. The Commission can just propose the status quo, if it wants to maintain it. Similarly, member state $k$ has no incentive to propose an amendment that includes policies that are not in the acceptance set $A_{N P}$. In equilibrium the mandate is thus in the acceptance set: $N M \subseteq A_{N P}$. For that reason we only consider mandates and amendments that are in that set in what follows.

In the fourth stage of the process the member states vote on the (amended) negotiating mandate NM. They look ahead and consider the policy that will be adopted if the mandate is granted. They vote in favor of the mandate if they 
prefer that policy to the status quo. That policy is preferred to the status quo by a qualified majority, as seen above, because any policy that is eventually adopted is preferred to the status quo by a qualified majority. A qualified majority thus votes in favor of the mandate.

In the third stage the member states vote on member state $k^{\prime}$ s amendment $N M_{k}$ to the mandate $N M_{C}$ proposed by the Commission. The amendment needs unanimous support for approval. Again, the member states look ahead. They consider the policy $p^{*}\left(N M_{k}\right)$ that will be adopted if the amendment is approved, and compare it to the policy $p^{*}\left(N M_{C}\right)$ that is adopted if the mandate proposed by the Commission is not amended. The member states then vote in favor of the amendment if they prefer policy $p^{*}\left(N M_{k}\right)$ to policy $p^{*}\left(N M_{C}\right)$.

For the amendment $N M_{k}$ to be approved the policy $p^{*}\left(N M_{C}\right)$ thus needs to be to the left (right) of all member states' ideal policies. Only then are there policies all member states prefer to it. It needs to be outside the support $S=\left[p_{1}, p_{n}\right]$ of the member states' ideal policies. This implies that the mandate $N M_{C}$ contains such policies, that is $N M_{\subset} \not \subset S$.

Suppose the mandate $N M_{\subset} \not \subset S$ and there are policies that can be adopted and are also in the support $S$, i.e. $A_{N P} \cap S \neq \varnothing$. All member states then prefer at least some of the policies in this intersection to the policy $p^{*}\left(N M_{C}\right)$. Thus, the mandate $N M_{C}$ can be amended. In fact, member state $k$ successfully proposes an amendment that is in this intersection in the second stage. 
Suppose the mandate $N M_{\subset} \not \subset S$ and there are no policies that can be adopted and are in the support $S$, i.e. $A_{N P} \cap S=\varnothing$. All member states then want to move farther away from the status quo than the trade partner or the EP are willing to accept. The best trade agreement the member states then can get is the agreement that makes the trade partner or the EP, whichever is closer to the status quo, indifferent to the status quo. If the Commission does not propose this policy as a mandate, the mandate $N M_{C}$ can be amended. ${ }^{15}$ In fact, member state $k$ then successfully proposes this policy as an amendment in the second stage.

Thus, for the mandate $N M_{C}$ not to be amended it needs to be in the support of the member states ideal policies, or, if no policy in the support can be adopted, it needs to be the policy that is closest to the support from among the policies that can be adopted. The negotiating mandate NM that emerges from the third stage of the process is thus either a subset of the support $S$, or it is the policy that is closest to $S$ from among the policies in the acceptance set $A_{N P}$. That is, the mandate $N M$ is a subset of the mandate set $M$, with $M=A_{N P} \cap S$ if $A_{N P} \cap S \neq \varnothing$, and $M=\left\{\min \left\{2 p_{T-}-q, 2 p_{E P}-q\right\}\right\}$ if $A_{N P} \cap S=\varnothing$.

In Figure 2 the support $S$ does intersect with the acceptance set $A_{N P}$. However, there are policies in the acceptance set that are to the left of all member states' ideal policies, to the left of $M S_{1}$. These policies are not in the mandate set $M=A_{N P} \cap S$. If the mandate $N M_{C}$ includes such policies, it can be amended.

In the second stage member state $k$ can propose an amendment to the mandate $N M_{C}$. If the mandate $N M_{C}$ is a subset of the mandate set, no amendment 
can be approved. Member state $k$ then chooses not to propose an amendment. Otherwise it proposes an amendment that is in the mandate set, as mentioned above.

In the first stage the Commission proposes a mandate. The agreement that is adopted at the end of the process needs to be within the mandate. The mandate thus constrains the Commission's choices when it proposes an agreement later on in the process. For this reason the Commission has no incentive to propose a mandate that is narrower than the mandate set. It will thus successfully propose as a mandate the mandate set: $N M=N M_{C}=M$. This is illustrated in Figure 2. In the Figure the Commission subsequently successfully proposes as trade agreement the policy $p^{*}=2 p_{E P-} q$ that makes the EP indifferent to the status quo. Proposition 1 summarizes the results.

Proposition 1 In trade negotiations the Commission successfully proposes as a negotiating mandate the set of policies that are preferred to the status quo by the pivotal member states, the EP and the trade partner, and are within the support of the member states' ideal policies. If no policy satisfies these conditions, it proposes the policy that is closest to the support of the member states' ideal policies and preferred to the status quo by the pivotal member states, the EP and the trade partner. The trade agreement that emerges from the process is the policy the Commission prefers most from among the policies in the negotiating mandate. 


\section{The Role of the Negotiating Mandate}

The negotiating mandate is an important feature of the EU's trade negotiation process. In an imperfect information world, in which the political actors do not know each other's preferences or the consequences of policies perfectly well, the process of setting the mandate provides an opportunity for the Commission and the member states to exchange information on preferences and the consequences of policies. It enables member states to give the Commission an idea of what policies they will accept at the end of the negotiation process, while allowing the Commission to choose different policies in response to what it learns about preferences and the consequences of policies in the negotiations with the trade partner.

Ours is a perfect information model, however, and thus the mandate does not convey any extra information in it. Nonetheless the mandate plays an important role in our model. It allows the member states to set limits on what the Commission can do in the negotiations with the trade partner. In particular we show that the mandate prevents the Commission from making an agreement with a trade partner, if there is another policy that would be adopted at the end of the process and is preferred to the agreement by all the member states.

The Council's right to set the negotiating mandate prior to the start of the negotiations with the trade partner is thus equivalent to a right to amend trade 
agreements prior to their adoption. For practical reasons trade agreements cannot be amended at the end of the process, because that would require the reopening of negotiations with the trade partner. Our paper shows that the Council has no need for such an amendment right, because it can achieve the same results by setting the negotiating mandate. Proposition 2 summarizes this result.

Proposition 2 The Council's right to set the negotiating mandate is equivalent to an amendment right.

Whereas the member states can use the negotiating mandate to limit the agreements the Commission can make, the Commission can use its right to propose the mandate to obtain a more advantageous agreement in the negotiations with the trade partner. In our model the Commission was assumed to have a monopoly proposal right and thus all the bargaining powers in the negotiations with the trade partner. So, it could obtain the agreement it liked most from among the policies in the mandate. The Commission then did not have an incentive to further limit the mandate.

If the trade partner does have bargaining powers, however, and the Commission does not obtain its most preferred agreement from the mandate as a result, then the Commission does have an incentive to restrict the mandate to make sure that it obtains the policy it prefers most from the mandate. It can 
achieve this by excluding from the mandate the policies that the trade partner prefers to its most preferred agreement. By restricting the mandate the Commission then obtains the same policy it would obtain if it had all the bargaining powers.

Suppose that in Figure 2 the trade partner had the same preferences as $\mathrm{MS}_{1}$, for example, and that she proposed the agreement in stage five. In that case the Commission would exclude the policies left of $2 M S_{1}$ from the mandate. The agreement that would emerge from the negotiating process would then be the policy $2 M S_{1}$ that makes member state 1 indifferent to the status quo.

Proposition 3 summarizes this result.

Proposition 3 The Commission's right to propose a negotiating mandate is equivalent to a monopoly proposal right in the negotiation process with the trade partner.

\section{The Impact of the Lisbon Treaty}

As a result of the Lisbon Treaty the EP's consent is required for the adoption of a trade agreement. Prior to the ratification of the Treaty in November 2009 this was not needed. The Treaty thus added one more condition for an agreement to be adopted in the last stages of the negotiation process: it reduced the acceptance set from $A_{T} \cap A_{Q M}$ to $A_{T} \cap A_{Q M} \cap A_{E P}$. The Treaty inserted an extra 
veto player in the trade negotiation process and limited the set of agreements that can be adopted, thus reducing the Commission's powers and the prospects for trade liberalization.

Our theory shows that the presence of an extra 'domestic' EU veto player in trade negotiations since the ratification of the Lisbon Treaty does not strengthen the bargaining position of the Commission in its negotiations with the trade partner, contrary to what the literature on the role of domestic constraints in international bargaining suggests (e.g. Putnam, 1988). This literature argues that the presence of a domestic veto player with more extreme preferences than the negotiator, may work to the advantage of the negotiator.

This argument would suggest that the Lisbon Treaty increased the Commission's bargaining powers. However, it presumes that the Commission did not already have all the bargaining powers. As we discussed in the previous section, the Commission can use its right to propose a mandate to strengthen its bargaining position in the negotiations and obtain its most preferred agreement from among the agreements that can be adopted. The Commission's right to propose the negotiating mandate thus effectively gives it all the bargaining powers. As a result the extra domestic constraint imposed by the Lisbon Treaty does not strengthen the Commission's bargaining powers in the negotiation process.

Proposition 4 summarizes this result. 
Proposition 4 The EP's involvement in the trade negotiation process does not strengthen the Commission's bargaining position in the negotiations with the trade partner, because the Commission can use its right to propose the negotiating mandate to this effect. The EP's involvement merely adds a veto player to the process, and thus reduces the set of agreements that can be adopted and the Commission's powers.

\section{Conclusions}

In this paper we formulated a game-theoretical model to analyze the EU's procedures for conducting international trade negotiations and study how the outcomes of the negotiations are affected by the increased involvement of the EP. Our model also offered important insights into the role of the negotiating mandate and its impact on trade agreements.

We found that the Commission includes in its mandate the policies that satisfy the following two conditions. First, they are preferred to the status quo by the trade partner, the EP, and a qualified majority of the member states. Policies that satisfy this condition can be adopted at the end of the process. Second, no policy that can be adopted is preferred to them by all member states. If the mandate includes policies that do not satisfy this second condition, it is amended prior to the start of the negotiations with the trade partner. 
We further found that if the Commission has all the bargaining powers in its negotiations with the trade partner, it successfully proposes the policy it likes most from among the policies in its mandate. If it does not have all the bargaining powers, it can achieve the same results by restricting its mandate.

We also concluded that the member states' right to amend the negotiating mandate prior to the start of the negotiations is equivalent to an amendment right after the negotiations.

Finally, our theory showed that the $\mathrm{EP}^{\prime}$ s increased involvement since the Lisbon Treaty's ratification does not strengthen the Commission's bargaining powers in the negotiation process. It merely adds a constraint and thus reduces the prospects for trade liberalization. At this point it is too early to test our theory empirically: only one trade agreement (with South Korea) has been concluded since the ratification of the Lisbon Treaty. 


\section{References}

Black, D (1958) The Theory of Committees and Elections. Cambridge: Cambridge University Press.

Crombez, C (1996) Legislative Procedures in the European Community. British Journal of Political Science 26: 199-228.

Crombez, C (1997) The Codecision Procedure in the European Union. Legislative Studies Quarterly 22: 97-119.

Crombez, C (2001) The Treaty of Amsterdam and the Codecision Procedure. In Schneider G and Aspinwall M (eds) The Rules of Integration: Institutional Approaches to the Study of Europe. Manchester: Manchester University Press, $101-22$

Crombez, C, Groseclose T and Krehbiel K (2006) Gatekeeping. Journal of Politics 68: $322-34$.

Damro, C (2007) EU Delegation and Agency in International Trade Negotiations: A Cautionary Comparison. Journal of Common Market Studies. 45: 883-903. Dür, A. (2008) Bringing Economic Interests Back into the Study of EU Trade Policy-Making. British Journal of Politics and International Relations. 10: 2745.

Franchino, F (2005) A Formal Model of Delegation in the European Union. Journal of Theoretical Politics , 17: 217-247. 
Kerremans, B (2003) Who Cares about Modalities? The European Commission and the EU Member States as Interdependent Actors in the WTO Negotiating Process. European Union Studies Association (EUSA) - Biennial Conference.

Meunier, S (2005) Trading voices: the EU in international negotiations. Princeton: Princeton University Press.

Moser, P (1997) A Theory of the Conditional Influence of the European Parliament in the Co-operation Procedure. Public Choice 91: 333-50.

Putnam, R (1988) Diplomacy and Domestic Politics: The Logic of Two-Level Games. International Organization. 42: 427-460.

Steunenberg, B (1994) Decision Making Under Different Institutional Arrangements: Legislation by the European Community. Journal of Institutional and Theoretical Economics 150: 642-69.

Thomson R (2011) Resolving Controversy in the European Union. Oxford: Oxford University Press.

Thomson, R et al. (2006) The European Union Decides: Testing Theories of European Decision-Making. Cambridge: Cambridge University Press.

Tsebelis, G (1994) The Power of the European Parliament as a Conditional Agenda Setter. American Political Science Review 88: 128-42.

Tsebelis, G and Garrett G (2000) Legislative Politics in the European Union. European Union Politics 1: 9-36. 
Van Gestel, W (2010) The Political Economy of EU Trade Policy: A Literature Review. Review of Business and Economics 55: 484-500.

Van Gestel, W and Crombez C (2011) The Role of the Trade Policy Committee in EU Trade Policy: A Political-Economic Analysis. Working Paper.

Woolcock, S (2008) The Potential Impact of the Lisbon Treaty on European Union External Trade Policy. European Policy Analysis. Swedish Institute for European Policy Studies. 


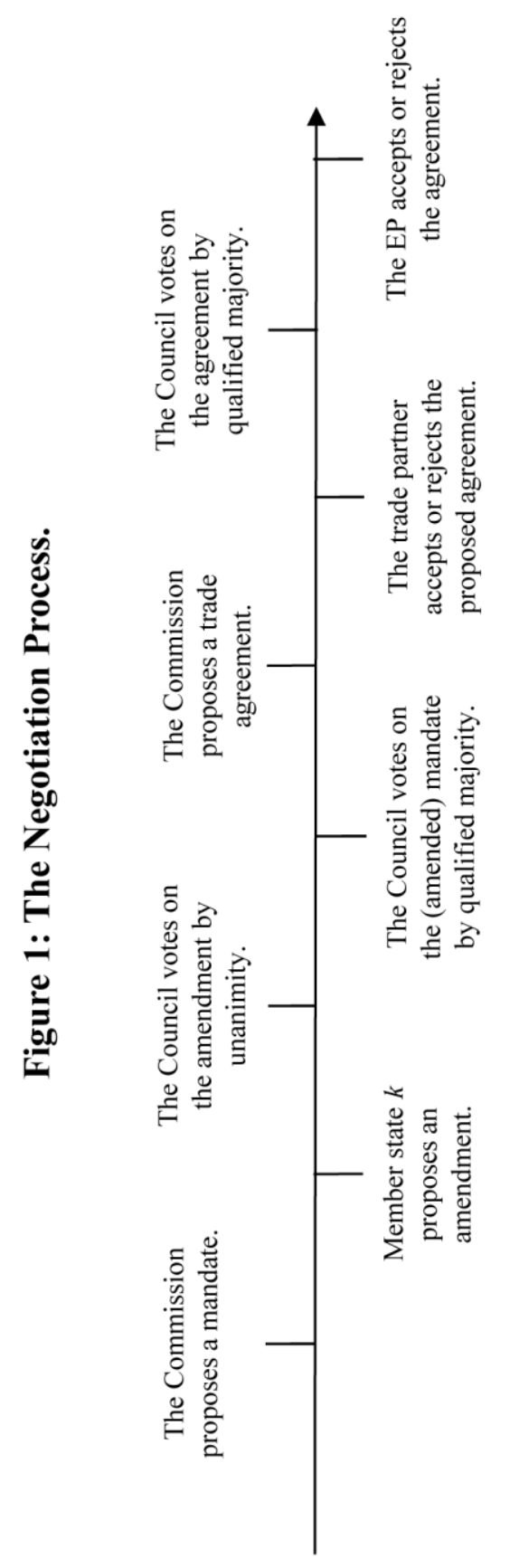




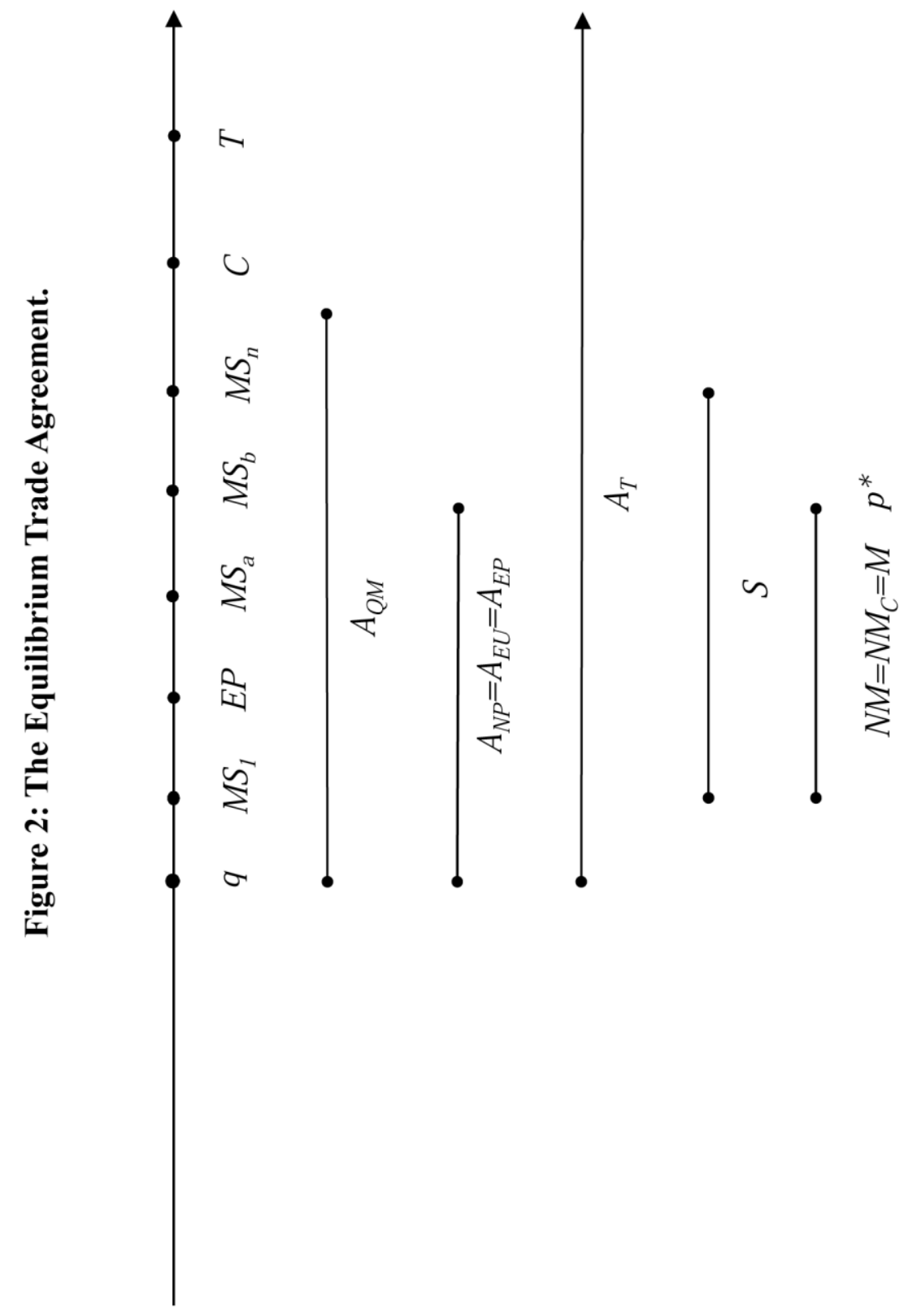


${ }^{1}$ There are three main institutions involved in EU policy making. The EP and the Council can be considered as the two chambers of a bicameral legislature. The EP is directly elected for five-year terms and represents the people. The member states are represented in the Council. The EP and the Council co-legislate on most important policy issues. The Commission is the EU's executive body. It also has monopoly proposal rights in the legislative process.

2 See, for example, Damro (2007), Dür (2008), Kerremans (2003), Meunier (2005) and Van Gestel (2010) for analyses of the reasons for and consequences of the delegation of trade policy to the Commission. See Franchino (2005) for a formal analysis of delegation in the EU.

${ }^{3}$ See Woolcock (2008) for an analysis of the Lisbon Treaty's impact on EU trade policy.

${ }^{4}$ See Articles 3 and 206 of the Treaty on the Functioning of the European Union (TFEU).

${ }^{5}$ See below for a definition and analysis of the qualified majority rule.

${ }^{6}$ See Article 16.3 of the Treaty on European Union (TEU) and TFEU 207.2 and 207.4.

${ }^{7}$ During the negotiations the Commission reports to the $\mathrm{EP}^{\prime} \mathrm{s}$ committee on international trade and consults the Council's trade policy committee. We present a perfect information model. In such a model these committees play no significant role. Therefore, we do not further discuss their roles. For an analysis of the trade policy committee's role in international negotiations, see Van Gestel and Crombez (2011).

8 The codecision procedure was introduced by the Maastricht Treaty in 1992. Subsequent treaties have extended its use. The Lisbon Treaty renamed it the ordinary legislative procedure. ${ }^{9}$ See TFEU 207.2 and 218.6.

10 See, for example, Crombez (1996, 1997, 2001), Moser (1997), Steunenberg (1994), Tsebelis (1994) and Tsebelis and Garrett (2000) for game-theoretical analyses of the legislative process. See Thomson (2011) and Thomson et al. (2006) for tests of such theories.

11 Our conclusions also hold in multi-dimensional models. We present a one-dimensional model merely because its verbal analysis and figures are less complicated. For the purposes of our analysis no additional insights would be gained from multi-dimensional models.

12 More precisely a qualified majority currently consists of: (1) 255 out of 345 votes; (2) from a majority of member states; (3) representing at least 62 percent of EU population. For simplicity, we ignore conditions (2) and (3), but this has no effect on the conclusions. The member states receive votes based on population, with the largest states getting 29 votes and the smallest having three. Under the provisions of the Lisbon Treaty the qualified majority rule will change in 2014. 
${ }^{13}$ The Commission does not have gatekeeping rights. See Crombez et al. (2006) for an analysis of gatekeeping.

${ }^{14}$ In the limited number of instances in which unanimity in the Council is required the set $A_{E U}=A_{E P} \cap A_{U N}$, where $A_{U N}$ is the unanimous Council's acceptance set, the set of policies all member states prefer to the status quo.

${ }^{15}$ Mandates and amendments are defined as sets. So, strictly speaking the mandate can be amended if it is not equal to the singleton that consists of the policy that makes the trade partner or the $\mathrm{EP}$, whichever is closer to the status quo, indifferent to the status quo. 